\title{
Supercritical synthesis of poly (2-dimethylaminoethyl methacrylate)/ferrite nanocomposites and online electrochemical monitoring of protein release
}

\author{
Gunjan Bisht ${ }^{1, *}$, M. G. H. Zaidi ${ }^{2}$ \\ ${ }^{1}$ Department of Natural Science, Kathmandu University, Dhulikhel, Nepal \\ ${ }^{2}$ Department of Chemistry, G. B. Pant University of Agriculture \& Technology, Pantnagar, India
}

Email address:

gunjanbisht31@gmail.com (G. Bisht)

\section{To cite this article:}

Gunjan Bisht, M. G. H. Zaidi. Supercritical Synthesis of Poly (2-Dimethylaminoethyl Methacrylate)/Ferrite Nanocomposites and Online Electrochemical Monitoring of Protein Release. International Journal of Biomedical Materials Research. Vol. 2, No. 1, 2014 , pp. 1-6. doi: $10.11648 /$ j.ijbmr.20140201.11

\begin{abstract}
A supercritical carbon dioxide (SCC) assisted process was developed to synthesize protein supported poly (2dimethylaminoethyl methacrylate)/ferrite nanocomposites (PNCs). The process involve 2,2-azobisisobutyronitrile initiated insitu polymerization of 2-dimethylaminoethyl methacrylate in presence of ferrite nanoparticles and bisacrylamide at $90 \pm 1$ oC, 1200 psi over $6 \mathrm{hr}$ in SCC. This was followed by subsequent loading of bovine serum albumin (BSA) as a model protein over PNCs in phosphate buffer (PBS, pH 7.4) at $1200 \mathrm{psi}, 35 \pm 1^{\circ} \mathrm{C}$ over additional $2 \mathrm{hr}$ in SCC. The formation of PNCs was ascertained through Ultra violet-visible, Fourier transform-infrared, X-ray diffraction spectra, transmission electron, atomic force microscopy and magnetometry. The developed process extends large scale production of nanomagnetic PNCs suitable as carrier for protein release applications with optimal release properties. The release of protein from PNCs under in vitro in PBS down to nanomolar range with high temporal resolution, speed and reproducibility was quantified through square wave voltammetry.
\end{abstract}

Keywords: Supercritical Synthesis, Nanocomposites, Protein Release, Square Wave Voltammetry

\section{Introduction}

The significance of supercritical fluids, particularly supercritical carbon dioxide (SCC) as a green friendly alternative to organic solvents has been of immense technological potential over past few decades [1-4]. Synthesis and processing of polymers and related nanomaterials for potential pharmaceutical and biomedical applications in SCC has been adopted either to develop the new technologies or to substitute the traditional technologies based on the use of organic solvents. Application of SCC offers an environmentally benign way of synthesis of materials that circumvent the energyintensive and expensive work-up procedures related with isolation of the products, removal of solvents and other by products through venting of carbon dioxide under ambient conditions [1]. Diffusion of SCC imparts increase in the free volume and mobility of the polymer chains that reduce their glass transition temperature and viscosity. This has developed many useful and sometimes unique, applications in pharmaceutical industry with emphasis on processing and production of drug nanoparticles $[1,4]$, labile proteins, peptides and lysozymes and their encapsulation into matrix of synthetic and biodegradable polymers for control release applications with additional advantages of the protection of the encapsulated molecules from degradation, their safe and target specific release to desired organs or tissues with minimized side effects [5-12].

Over past decades, in order to address the challenges of green analytical chemistry, extensive efforts were made on development of the protocols for online monitoring of the released pharmaceuticals from various substrates with negligible waste generation [13-15].In this context, analytical techniques based on high performance liquid chromatography coupled with isotopic dilution mass spectrometry [16], size exclusion chromatography [17,18], bicinchoninic acid assay [19], mass spectrometry [20,21], electrochemical methods based on square wave voltammetry [15] and potentiometric drug selective electrodes [22] have received increasing popularity towards quantification of proteins. Among such methods, 
Electroanalytical methods based on square wave voltammetry has claimed to provide the quantification of analytes of biomedical relevance with high sensitivity and reproducibility while concurrently minimizing the errors and costs incurred in the collection and handling of individual sample aliquots [16-21].

Recently, increasing attentions has been made on synthesis of multifunctional polymer nanocomposites involving magnetic nanoparticles applicable as carriers for target specific drug delivery applications [23-28]. For large scale production of such materials there is a continuous need of those processes that may either proceed under solid phase or through environmentally benign procedures involving supercritical fluids. In this context, although, recently, the proposed class of PNCs and alike systems were synthesized through solvent assisted insitu polymerization method [2932], no efforts are made to synthesize the proposed class of nanomagnetic PNCs in SCC. Realizing the technological benefits associated with applications of supercritical fluids as a medium of processing of materials [1-4], a SCC assisted process has been developed to synthesize the protein supported PNCs, wherein the polymer matrix may shrink due to localized heating triggered by magnetic response of the nanoparticles to provide an optimal on-off release to the loaded protein from such PNCs [26, 33-36]. The release of BSA as a model protein from PNCs under in vitro has been quantified in PBS down to nanomolar range with high temporal resolution, speed and reproducibility through square wave voltammetry [13-15].

\section{Experimental}

\subsection{Materials}

The monomer 2-dimethylaminoethyl methacrylate (DMAEMA) and crosslinking agent N, N'-methylene-bisacrylamide (MBA) were procured from Polyscience USA. 2,2-azobisisobutyronitrile (AIBN) and BSA were purchased from Ms Himedia Chemicals India and used without further purification. Other chemicals, solvents (AR grade) and $\mathrm{CO} 2(99.9 \%)$ were purchased locally. The inhibitor content of DMAEMA has been removed through distillation under reduced pressure. Ferrite nanoparticles (FNPs) were prepared according to the procedure reported [37]. In brief, ammonium hydroxide $(7.0 \mathrm{M}, 50 \mathrm{~mL})$ has been gradually added at the rate of $\sim 1 \mathrm{cc} / \mathrm{sec}$ to the aqueous solution containing $\mathrm{FeCl} 2.4 \mathrm{H}_{2} \mathrm{O}(3 \% \mathrm{w} / \mathrm{v})$ at $90{ }^{\circ} \mathrm{C}$. In the early stage of the reaction, brown precipitate was formed that was isolated through filtration and subsequently dried overnight in air at room temperature to provide FNPs.

\subsection{Processing of Protein Supported PNCs in SCC}

The PNCs was synthesized in a stainless steel high pressure reactor $(100 \mathrm{~cm} 3)$, model $\mathrm{MC} \quad 10 \quad 10$ SI ST equipped with a PID temperature controller, manufactured by Pressure Products Industries, Warminster, Penn., USA. The temperature inside the cell was measured by an industrial insulated thermocouple provided and displayed on the PID temperature controller. The reactor was charged with a requisite quantity $(\mathrm{mol} / \mathrm{dL})$ of monomer $(6.5 \times 10-3)$, AIBN (1.5X10-3), MBA (9.5 X10-4), FNPs (2.5 phr) and $\mathrm{CO} 2$. The reaction mixture has been gradually heated with electrically heating tape wrapped around the exterior wall of the cell at $90 \pm 1^{\circ} \mathrm{C}$ to obtain the desired pressure of 1200 psi. At this stage the reaction mixture was allowed to reflux over 6 hrs. The $\mathrm{CO} 2$ was vented into dichloromethane from the cell at $25 \pm 1^{\circ} \mathrm{C}$ and PNCs with yield (\%) 84.7 were isolated. In order to synthesize the protein supported PNCs, reactor was recharged with PNCs (20 mg) along with solution of BSA $(1 \mathrm{mg} / \mathrm{mL}, 10 \mathrm{~mL})$ in phosphate buffer solution (PBS, pH 7.4) and $\mathrm{CO} 2$. The contents were pressurized at 1200 psi over $2 \mathrm{hrs}$ under SCC at $35 \pm 1^{\circ} \mathrm{C}$ [5] . BSA supported over PNCs has been isolated through depressurizing the reactor at ambient temperature followed by their magnetically driven isolation from the reactor vessel. PDMAEMA with yield (\%) 88.5 and respective BSA supported PDMAEMA has also been synthesized under the identical conditions.

\subsection{Characterization}

UV-vis spectra were recorded in methanol over spectrophotometer model Genesis 10 Thermospectronic USA at the increment of $3 \mathrm{~nm}$. Fourier transformedinfrared (FT-IR) spectra were obtained over Perkin Elmer spectrometer in $\mathrm{KBr}$. X-ray diffraction (XRD) spectra were recorded over Rigaku-Geiger Flex diffractomer with $\mathrm{CuK} \alpha$ radiation of wavelength $1.54056 \AA$ at $2 \theta$ ranging $20-80^{\circ}$ with scan rate of $10^{\circ} \mathrm{min}-1$. Phase identification of materials has been performed by matching peak positions and relative intensities to reference JCPDS file. The average crystal size of FNPs has been calculated according to Debye Scherer's formula: $\mathrm{D}=\mathrm{K} \lambda / \beta \cos \theta$, where $\lambda$ is the $\mathrm{X}$-ray wavelength and $\mathrm{K}$ is the shape factor, which can be assigned a value of $0.89, \cos \theta$ is the cosine of the Bragg angle and $\beta$ is the half height of diffraction angles in radians. For atomic force microscopy (AFM), samples were prepared through sonication in acetone $(1 \%, \mathrm{w} / \mathrm{v})$ and an aliquot $(1 \mu \mathrm{L})$ was deposited over borosilicate glass slides of $1 \mathrm{~cm} 2$ area. AFM images were recorded over NTEGRA Prima atomic force microscope under tapping mode at $2 \mu \mathrm{m}$ scale under ambient conditions. For transmission electron microscopy (TEM), the requisite volumes of the samples sonicated in acetone $(1 \%, \mathrm{w} / \mathrm{v})$ were applied over grid. TEM images were recorded at 10KX magnification and $0.2 \mu \mathrm{m}$ scale over JEOL 1011 (Tokyo, Japan) at $80 \mathrm{kV}$. Magnetometry data were recorded over vibration sample magnetometer, Princeton EG\&G applied research model 155 with maximum current 30 A, reading Number.150, scan time-900 seconds at room temperature.

The protein release behavior from PNCs has been monitored through square wave voltammetry over IVIUM Potentiostat Galvanostat equipped with an electrochemical cell $(20 \mathrm{~mL})$, glassy-carbon working electrode $(2 \mathrm{~mm}$ 
diameter), Pt wire counter electrode (1 $\mathrm{mm}$ diameter) and an $\mathrm{Ag} / \mathrm{AgCl}$ reference electrode. The carbon working electrode was initially polished with $3 \mu \mathrm{m}$ and $0.05 \mu \mathrm{m}$ alumina slurries, followed by rinsing with water and a 3 min sonication. This mechanical cleaning procedure was performed only once, before a series of runs. The electrochemical data has been analyzed through IVIUMSOFT VS.1.821 software. Optimized square wave voltammetry parameters included a potential scan between $0.0 \mathrm{~V}$ and $-1.1 \mathrm{~V}$, at a frequency of $25 \mathrm{~Hz}$, amplitude of 10 $\mathrm{mV}$ and a step of $2 \mathrm{mV}$ [15].

\section{Results and Discussions}

Poly (dimethylaminoethyl methacrylate) /ferrite nanocomposites (PNCs) for protein release applications has been synthesized through AIBN initiated polymerization of DMAEMA monomer in presence of MBA as crosslinker and FNPs (2.5 phr) at $90 \pm 1^{\circ} \mathrm{C}, 1200$ psi over $6 \mathrm{~h}$ in SCC. The formation of FNPs, PDMAEMA and corresponding PNCs has been ascertained through their spectra, microscopy and magnetic behavior. UV-vis spectra of FNPs, MBA and DMAEMA reveal their respective absorptions (nm) at 212, 233 and 251. AIBN initiated polymerization of DMAEMA in presence of MBA in SCC has afforded PDMAEMA with a pair of absorptions at 227 (weak) 245 (strong) nm. Such blue shift in the absorption of PDMAEMA over monomer may be assigned to the loss of the unsaturation of the vinyl functionality as a result of polymerization reaction (Figure 1). Polymerization of DMAEMA in presence of MBA and FNPs under identical reaction conditions afforded PNCs with absorption at 227 nm. Such blue shift in the absorption of PNCs over PDMAEMA may be assigned to the development of the amine functionality over FNPs assisted with PDMAEMA. FNPs reveals characteristic FT-IR spectral assignments (cm-1) (Figure 2 a) at $3519.3(v \mathrm{O}-\mathrm{H}), 2147.6$ ( $v \mathrm{CO} 2)$, $585.1(v$ Fe-N), $549.5(v$ Fe-O), $473.8(\delta$ Fe-N). A shift in the characteristic wave numbers in the FT-IR spectra corresponding to FNPs from $585.1(v$ Fe-N) and $473.8(\delta$ $\mathrm{Fe}-\mathrm{N})$ to higher wave numbers at $590(v \mathrm{Fe}-\mathrm{N})$ and $510(\delta$ $\mathrm{Fe}-\mathrm{N}$ ) further supports the formation of $\mathrm{Fe}-\mathrm{N}$ bonding in PNCs (Figure $2 \mathrm{c}$ ), While peaks corresponding to $\mathrm{Fe}-\mathrm{N}$ and $\mathrm{Fe}-\mathrm{O}$ bonding are completely absent in FT-IR spectra of PDAEMA (Figure 2b) [37].

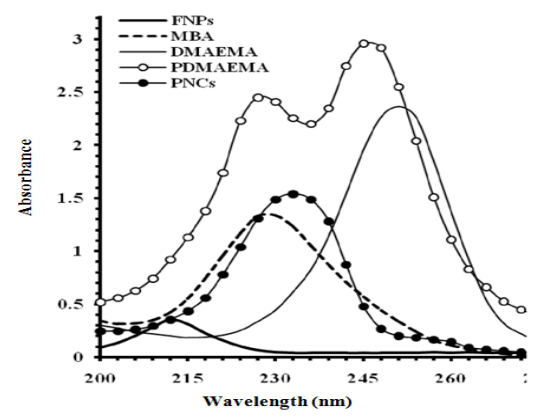

Figure 1. UV Spectra

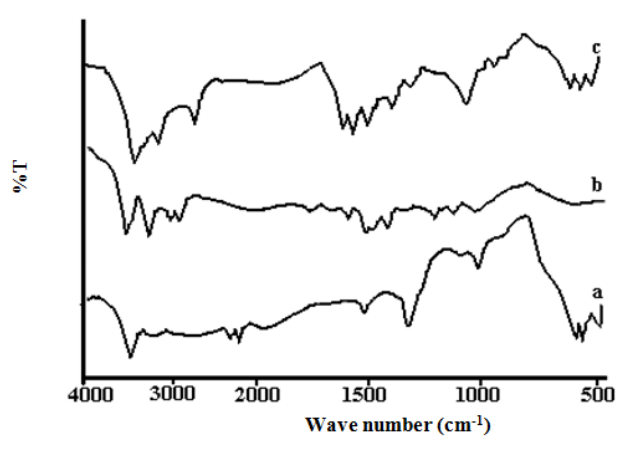

Figure 2. FT-IR Spectra. of FNPS (a), DMAEMA (b) and PNCs (c).

Figure 3 represents the XRD spectra of FNPs, PNCs and PDMAEMA microspheres. PDMAEMA shows characteristic broad peak at about $2 \theta=20^{\circ}$ that indicates its amorphous behavior FNPs (PNCs) shows diffraction peaks corresponding to hkl at 220,311,400, 333 and 440 at $2 \theta$ values at 30.054 (29.914), 35.447 (35.039), 43.123 (42.815), 57.217 (56.708) and 62.630 (62.406) indicating their magnetite structure (Figure $3 \mathrm{a}$ and 3c) [41]. The respective hkl values of FNPs are in close agreement with ASTM data [42]. Calculations based on Debye Scherrer equation at the highest reflecting peak at $2 \theta(\mathrm{hkl})=$ $35.039^{\circ}(311)$ indicates the average crystallite size of FNPs about $19.5 \mathrm{~nm}$.[43].

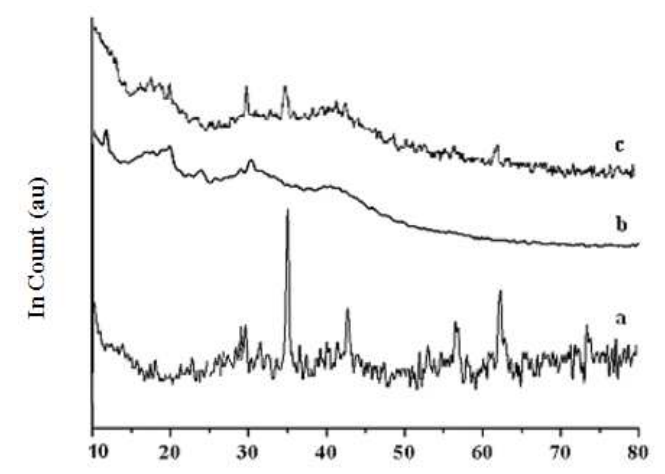

Figure 3. XRD Spectra of FNPs (a), DMAEMA (b) and PNCs (c).
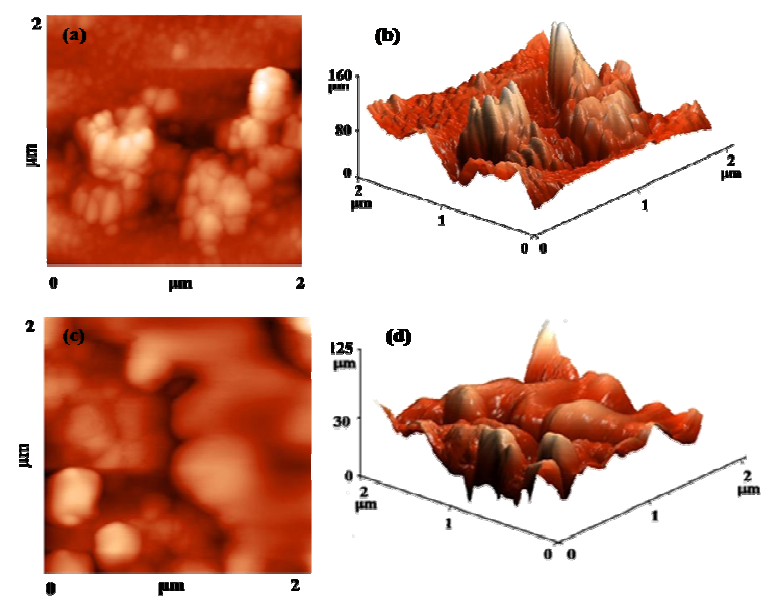

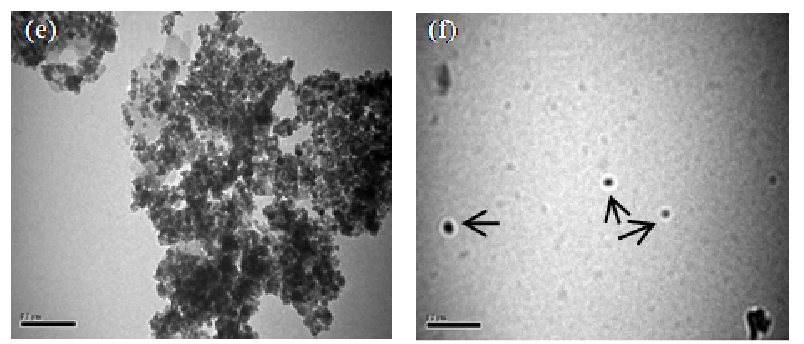

Figure 4. AFM images of PDMAEMA (a-b) and PNCs (c-d).TEM images of FNPS (e) and PNCs (f).

Figure 4 shows the surface morphology of the PDMAEMA and respective PNCs investigated through AFM scanned under identical conditions. In order to achieve results to be comparable, the each of the AFM micrographs has been obtained at identical XY scale of 2 $\mu \mathrm{m}$ and the indenter height ( $\mathrm{Z}$ scale) has been confined in the closed vicinity. PDMAEMA indicates non uniform distribution of agglomerated grains with average size confined in the range of 100-220 nm (Figure 4a-4b) [44]. Presence of FNPs in the PDMAEMA matrix has enhanced the grain size of PNCs ranging 180 to $600 \mathrm{~nm}$. Qualitatively, the grains of PNCs have been less agglomerated probably due to the dispersion of the FNPs into PDMAEMA (Figure 4c-4d). In order to have further insight into the quality of dispersion of FNPs into PDMAEMA, TEM image of FNPs and PNCs has been recorded. A comparative account of the TEM images reveals the presence of aggregates of the FNPs (Figure 4e), whereas a well distribution of FNPs with their distinct visibility into PDMAEMA matrix has been observed at 10 KX magnification and $0.2 \mu \mathrm{m}$ scale (Figure $4 \mathrm{f}$ ).

The magnetic behavior of materials depends on many factors, such as elemental composition, crystallinity, shape, size and orientation [41]. As the size of the magnetic materials increases, their coercivity and remanence increase accordingly [37]. Figure 5 shows the hysteresis loop of FNPs and corresponding PNCs at room temperature In agreement with the predictions of the particle size from AFM, TEM and XRD data, it can be found that, with increase in the particle size, FNPs show lower coercivity (89.09 Oe) over PNCs (153.2 Oe) with simultaneous increase in their remanence of 8.35 and 0.02 $\mathrm{emu} / \mathrm{g}$ (inset figures). This has further contributed a reduction in the saturation magnetization $(\mathrm{emu} / \mathrm{g})$ of PNCs (0.11) over FNPs (68.55) [45].

Ability to monitor the online release of BSA from PDMAEMA and respective PNCs at the initial stage of release is a major advantage of the square wave voltammetry [15]. In the in-vivo environment, drug delivery carriers experience general $\mathrm{pH}$ conditions: $\mathrm{pH}=7.4$ while circulating in the blood. For this reason, the online monitoring of the BSA release from the synthesized materials has been investigated in PBS at $\mathrm{pH}$ 7.4. Figure 6a display square-wave voltammograms at increasing
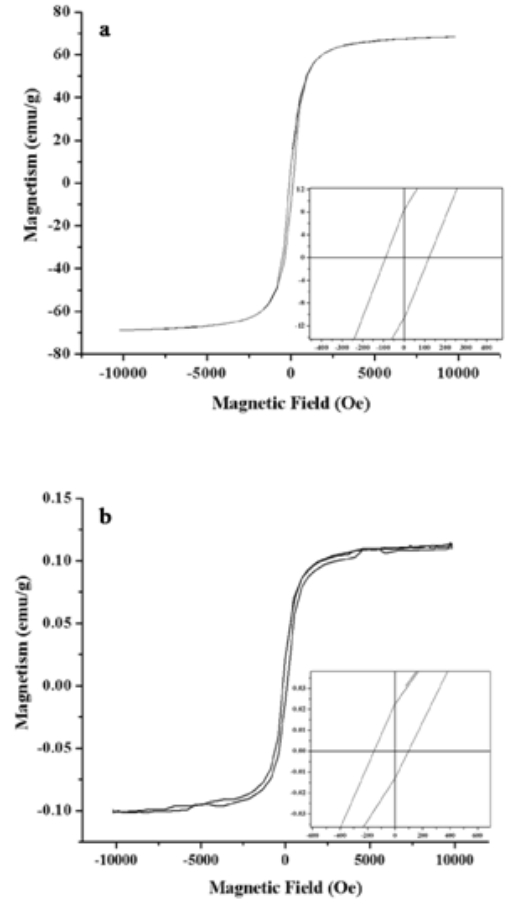

Figure 5. Hysteresis curve of the FNPS (a) and PNCs (b).

concentrations of BSA ranging 0.1 to $0.6 \mathrm{mg} / \mathrm{mL}$ with well defined voltammetric peaks at $-0.73 \mathrm{~V}$. Such favorable signal-to-background characteristic offers convenient measurements of the sub-micromolar concentrations of BSA release from PDMAEMA and respective PNCs. With BSA concentration, the peak intensity has been proportionally decreased over the entire range of current due to accumulation of BSA on glassy carbon electrode. The corresponding calibration plot is highly linear, with a correlation coefficient of 0.994 (Figure 6b). With BSA release, the stability of the reduction signal was evaluated in PBS. Figure 5 display the stability of the response for a BSA solution $(1 \mathrm{mg} / \mathrm{mL})$ in PBS during a series of 6 successive measurements over 120 min period of continuous monitoring. A highly stable response has been observed, without apparent loss in sensitivity over the period, providing high sensitivity of the voltammetric protocol coupled with high reproducibility and stability, essential for continuous monitoring of release of BSA [15]. by its slower release in the second step. Measurement of Figure 7 shows progress of the release of BSA in PBS ( $\mathrm{pH}$ 7.4). The release curves were obtained by monitoring the voltammetric signals of BSA at the intervals of 20 minutes over 120 minutes immediately following the addition of BSA loaded particles. Figure $7 \mathrm{a}$ display the stability of the response for a BSA solution $(1 \mathrm{mg} / \mathrm{mL})$ in PBS during a series of 6 successive measurements over a 120 min period of continuous operation. The release of BSA from PDMAEMA and PNCs was observed in two steps. which means that the The first step comprised relatively fast release of BSA followed 


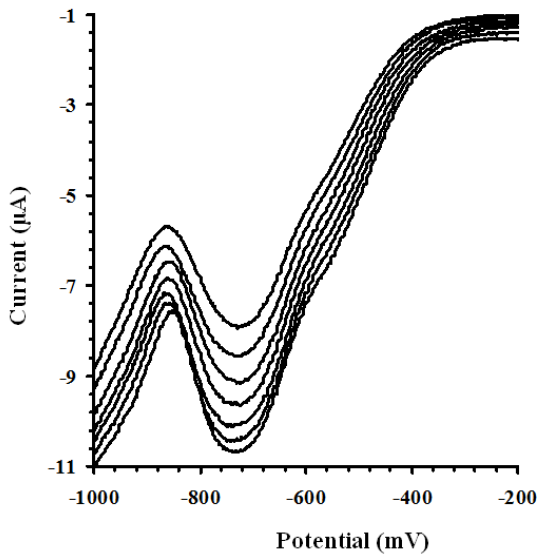

Figure 6 a. Square Wave Voltammograms of BSA at concentration $(\mathrm{mg} / \mathrm{mL})$ ranging 0.1-0.6 in PBS (7.4 pH).

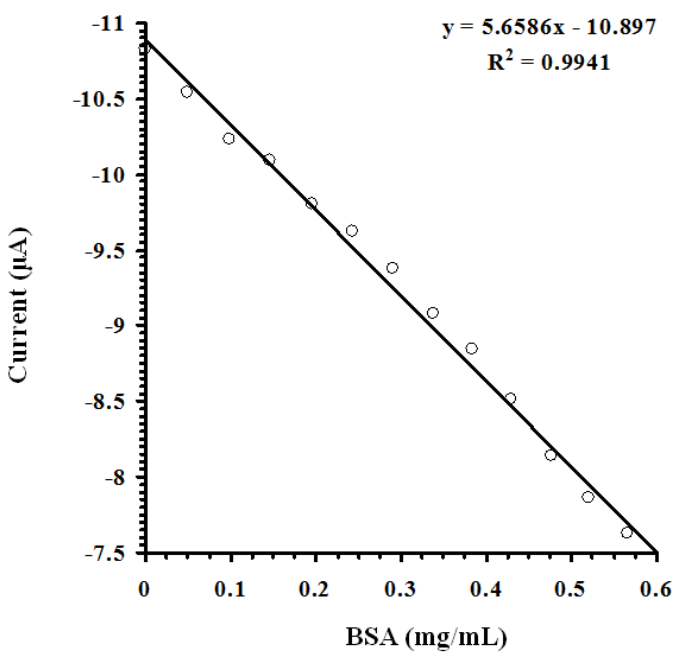

Figure 6 b. Calibration curve for BSA.

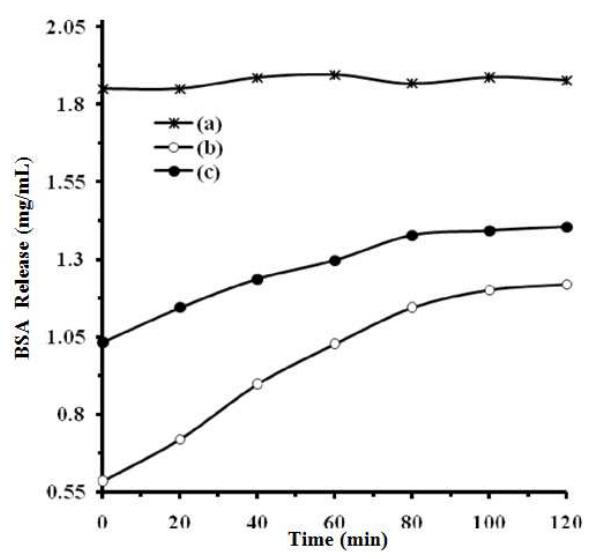

Figure 7. RT electrochemical Monitoring of BSA $(1.0 \mathrm{mg} / \mathrm{mL})$ release from control (a), PNCs (b) and PDMAEMA (c).

the fast initial release is easier and more reliable with the new online monitoring capabilities of electrochemical sensor. Traditional methods of measuring release require considerable sample preparation time, fast initial release has likely already occurred with time or measurement begins. The PNCs shows slow and sustained release in comparison to PDMAEMA (Figure 7b-7c).The rate of release during the initial fast-release period was considerably higher for the PDMAEMA over the polymer nanocomposite, with a very rapid release PDMAEMA of 10.3 wt. \% during the first 20 min followed by a slow quasi-steady state release. In contrast, the release from PNCs was 5.8 wt. \% within the initial 20 min, followed by a gradual release sustained over the remaining $100 \mathrm{~min}$. Faster release from the PDMAEMA over PNCs can be more elaborately expressed with the observation that about $10 \mathrm{wt} \%$ of BSA was released from PDMAEMA in first 10 min while corresponding PNCs takes around $60 \mathrm{~min}$ for $10 \mathrm{wt} \%$. Such fast release of BSA from PDMAEMA may be attributed to the graeter adherence of the BSA over the surface of the PDMAEMA than PNCs under executed conditions of the loading of BSA in SCC which released frequently in initial phase. After $120 \mathrm{~min}$, a characteristic controlled release behavior of BSA $(\mathrm{mg} / \mathrm{mL})$ from PNCs (1.397) over PDMAEMA (1.414) has been observed [15].

\section{Conclusion}

A SCC assisted environmentally benign method of processing of protein supported poly dimethylaminoethyl methacrylate (PDMAEMA)/ferrite nanocomposites (PNCs) has been developed. The developed process holds significance of large scale production of protein supported nanomagnetic PNCs with optimal release properties. Spectral, microscopic and magnetometry data reveals the formation of PNCs. A direct and reliable quantification of the release BSA from PNCs and respective PDMAEMA with high electrochemical sensitivity, reproducibility and stability has been achieved through online square wave voltammetry in phosphate buffer solution at $\mathrm{pH}$ 7.4. At initial stages of time, PNCs rendered comparatively slow and sustained release of BSA over PDMAEMA that was turned into a distinct controlled release behavior of BSA $(\mathrm{mg} / \mathrm{mL})$ from PNCs (1.39) over PDMAEMA(1.41) after $120 \mathrm{~min}$.

\section{Acknowledgements}

The financial support of the University Grants Commission (U.G.C.), India for the execution of the present research work is acknowledged. The author G. Bisht acknowledges U.G.C. and Jawaharlal Nehru Memorial Fund for the award of the research fellowship.

\section{References}

[1] Brunner, G . Ann Rev Chem. Biomol. Engg.2010, 1, 321.

[2] Ohde, H, Wai, C.M, Rodriguez, J.M, Coll. Polym. Sci. 2007, 285,475 .

[3] Cao, L, Chen, L, Jiao, J , Zhang, S , Gao, W. Coll. Polym. Sci.2007, 285, 1229 .

[4] Pathak, P , Meziani, M.J , Sun, Y.P . Exp. Op. Drug Del. 2,747 . 
[5] Watson, M.S , Whitaker, M. J , Howdle, S.M , Shakesheff, K.M .Adv. Mat.2002,14, 1802.

[6] Hile, D.D , Pishko, M.V. J. Del. Targ. Therap. Agents.2004,11, 287.

[7] Caliceti, P, Salmaso, S , Elvassore, N , Bertucco, A. J.Control Release.2004,94, 195.

[8] Ginty, P.J, Barry, J.J.A , White, L.J , Howdle, S.M, Shakesheff, K.M. Eur J. Phar. Biopharmaceutics,2008, 68, 82.

[9] Kang, Y, Yang, Y, Ouyang, C, Yin, P, Huang, G, Yao, Z, Liao, Y. Carbohydrate Polym.2009, 7, 244.

[10] Kluge, J, Fusaro, F, Casas, N, Mazzotti, M, Muhrer, G. J. Supercrit. Fluids.2009,50, 327.

[11] Wang, C, Wang, J, Gao, W, Jiao, J, Feng H, Liu, X, Chen, L. J. Coll. Interf. Sci.2010, 343, 141.

[12] Yang, Y, Tang, G, Zhang, H, Zhao, Y, Yuan, X, Fan, Y, Wang, M. Mat. Sci. Engg.2011, C31, 350.

[13] Wang, J. .Acc. Chem. Res. 2002, 35,811.

[14] Schwarz, A, Bagel, O, Girault ,H.H. Electroanalysis.2000, 12,811 .

[15] Mora, L, Torres, K.Y.C, Clawson, C, Hernandez, L, Zhang, L, Wang, J. J. Control Release, 2009, 140,69.

[16] Kato, M, Kato, H, Eyama, S, Takatsu, A.J. Chromatogr. B: Analytical Technologies in the Biomedical and Life Sciences. 2009, 877,3059 (2009)

[17] Carpenter, J.F, Randolph T.W, Jiskoot F, Crommelin, W.D.J, Middaugh, C.R, Winter G. Pharm. Sci.2010, 99,2200.

[18] Horak J, Ronache,r A, Lindner, W. J, Chromatogr . 1217, 2010,5092

[19] Carlsson, N, Borde, A, Wölfel, S, Åkerman, B, Larsson, A. Anal. Biochem.2011, 411, 116.

[20] Pan, S, Aebersold, R, Chen, R, Rush, J, Goodlett, D.R, McIntosh, M.W, Zhang, J, Brentnall, T.A. J. Proteome Res. $2009,8,787$.

[21] Ye, H, Hill, J, Kauffmanm, J, Han, X. Anal. Biochem.2010, 400,46

[22] Tan J.P.K, Tam K.C. J. Control Release. 2007, 118, 87.

[23] Thatiparti, T.R, Muram, S.T, Nivasu, V.J. Biomed. Mat. Res. B: Appl. Biomat. 92B, 111.

[24] Yiu, H.H.P, Niu, H.J, Biermans, E, Tendeloo, G.V, Rosseinsky, M.J. Adv. Funct. Mat. 2010, 20, 1599.

[25] Phanapavudhikul, P, Shen, S, Ng, W.K, Tan, R.B. Drug Deliv. 2008, 15, 177 .
[26] Hoare, T, Antamari, J.S, Goya, G.F, Irusta, S, Lin, D, Lau, S, Padera, R, Langer, R, Kohane, D.S. Nano Lett.2009, 9,3651.

[27] Ke, F, Yuan, Y.P, Qiu, L.G;. Shen, Y.H, Xie, A.J, Zhu, J.F, Tian, X.Y, Zhang, L.D. J. Mater. Chem. 2,3843.

[28] Li, W, Gao, C, Qian, H, Ren, J, Yan, D.J Mater Chem. 2006, $16,1852$.

[29] Dong, H, Huang, J, Koepsel, R. R, Ye, P, Russell, A. J, Matyjaszewski, K. Biomacromolecules. 12, 1305.

[30] Zhou, L, Yuan, J, Yuan, W, Sui, X, Wu, S, Li, Z, Shen, D.J. J. Magn. Magn. Mater.2011, 2011, 321,2799.

[31] Zhou, L, Cai, Z, Yuan, J, Kang, Y, Yuan, W, Zhong, D. Polym Int.2011, 60, 1303.

[32] Nguyen, H, Haldorai, Y, Pham, Q. L, Shim, J. J. Mat. Sci. Engg. B.2011, 173, 773.

[33] Sun, Y, Chen, Z. L, Yang, X. X, Huang, P, Zhou, X. P, Du, X. X. Nanotechnology. 2009, 20, 135102.

[34] Chomoucka, J, Drbohlavova, J, Huska, D, Adam, V, Kizek R, Hubalek, J. Pharm. Res. 2010, 62, 144.

[35] Purushotham, S, Ramanujan, R.V. Acta Biomaterialia.2010, 6,502 .

[36] McGill, S. L, Cuylear, C. L, Adolphi, N. L, Osi'nski, M, Smyth, H. D. C., IEEE Transsaction on Nanobiosci. 2009, 8, 33.

[37] Agarwal, T, Gupta, K, Zaidi, M. G. H, Alam, S. Nanoscience and Nanotechnology, 2012, 2, 5.

[38] Jin, L, Deng, Y, Hu, J, Wang, C. J. Polym. Sci. A: Polym. Chem. 42,2011, 6081 .

[39] Dai, F, Sun, P, Liu, Y, Liu, W. Biomaterials.2010, 31,559.

[40] Zhang, X. Ai , C, Ma, J, Xu J, Yang, S. J. Colloid Interf. Sci.2001, 356, 24.

[41] Chen, L, Xie, J, Aatre, K.R, Varadan, V.K. J. Nanotech. Engg. Med. 2010, 1(1), 8 pp.

[42] Gou, M. L, Qian, Z.Y, Wang, H, Tang, Y.B, Huang, M.J, Kan, B, Wen, Y.J, Dai, M, Li, X.Y, Gong, C.Y, Tu, M.J. J Mater Sci, Mater Med.2008, 19,1033.

[43] Jia, Y, Gray, G.M, Hay, J.N, Li, Y, Unali, G.F, Baines, F.L, Armes, S.P Mater. Chem.2005, 15, 2202.

[44] Xie, M, Kong, Y, Han, H, Shi, J, Ding, L, Song, C, Zhang, Y. React. Funct. Polym.2008, 68, 1601.

[45] Pimpha, N, Chaleawlert, S, Chruewkamlow N , Kasinrerk W, Talenta 2011, 84,89. 